\title{
Virulence and Molecular Diversity of the Puccinia striiformis f. sp. tritici Population in Xinjiang in Relation to Other Regions of Western China
}

Gangming Zhan, Fuping Wang, Cuiping Wan, Qingmei Han, Lili Huang, and Zhensheng Kang, State Key Laboratory of Crop Stress Biology for Arid Areas and College of Plant Protection, Northwest A\&F University, Yangling, Shaanxi 712100, P. R. China; and Xianming Chen, United States Department of Agriculture-Agricultural Research Service, Wheat Genetics, Physiology, Quality, and Disease Research Unit, and Department of Plant Pathology, Washington State University, Pullman 99164-6430

\begin{abstract}
Zhan, G. M., Wang, F. P., Chen, X. M., Wan, C. P., Han, Q. M., Huang, L. L., and Kang, Z. S. 2016. Virulence and molecular diversity of the Puccinia striiformis f. sp. tritici population in Xinjiang in relation to other regions of western China. Plant Dis. 100:99-107.

In recent years, wheat stripe rust caused severe yield losses in western China, especially the Xinjiang Autonomous Region. The population of the stripe rust fungus Puccinia striiformis $\mathrm{f}$. sp. tritici in the vast region had not been well studied. To determine the population structure and compare it with the populations in the neighboring provinces or autonomous regions, $P$. striiformis $\mathrm{f}$. sp. tritici isolates from Xinjiang, Qinghai, Gansu, Ningxia, and Tibet in western China were characterized by virulence tests with 19 wheat genotypes that are used to differentiate races of $P$. striiformis f. sp. tritici in China and by genotyping tests with 15 simple-sequence repeat (SSR) markers. In total, 56 races, including 39 previously known and 17 new races, were identified from 308 isolates obtained from the three epidemiological regions covering five provinces,

of which 27 previously known and 8 unknown races were detected in Xinjiang, higher than the numbers in either of the other two regions. The races in Xinjiang consisted of those historically and recently predominant races in other regions of China. The $P$. striiformis $\mathrm{f}$. $\mathrm{sp}$. tritici population in Xinjiang had a higher genetic diversity than populations in other epidemiological regions. Molecular variation among subpopulations within Xinjiang was higher than in other regions. Both virulence and molecular data indicate that the $P$. striiformis $\mathrm{f}$. sp. tritici population in Xinjiang is related to but more diverse than those in other epidemiological regions. The results show that Xinjiang is an important stripe rust epidemiological region in China, and the information should be useful for control of the disease in the region as well as in other regions.
\end{abstract}

Wheat stripe rust, caused by Puccinia striiformis f. sp. tritici Erikss., is one of the most important diseases of wheat worldwide (Chen 2005; Wellings 2011). In China, stripe rust is considered the most important disease of wheat, because it has caused huge yield losses and large-scale application of fungicides (Chen et al. 2014; Li and Zeng 2002; Wan et al. 2007). Breeding for resistance is the most effective strategy to control stripe rust. However, due to the rapid race changes in the pathogen population, wheat cultivars previously resistant to stripe rust can become susceptible after only a few years of cultivation (Chen 2005; Kang et al. 2010; Wan et al. 2007). Since the 1950s, China has experienced nine epidemics of wheat stripe rust that resulted in the loss of resistance in a large number of cultivars due to the emergence of new races (Kang et al. 1987; Li and Zeng 2002). Thus, studying the $P$. striiformis f. sp. tritici populations, especially virulence changes, is crucial for control of the disease.

Zeng and Luo (2006) classified China into 15 stripe rust epidemiological regions (ER) based on climates, wheat cropping systems, pathogen survival, and geographic barriers for preventing or reducing urediniospore spread. The Xinjiang Autonomous Region, about $17 \%$ of the total area of China, is the largest ER and separated from other regions by mountains and deserts (Wan et al. 2007; Zeng and Luo 2006). Wheat is a major staple food crop for people living in the region. According to a recent archeological discovery, wheat

Corresponding authors: Z. S. Kang, E-mail: kangzs@nwsuaf.edu.cn; and Q. M. Han, E-mail: hanqm@nwsuaf.edu.cn

G. Zhan and F. Wang contributed equally to this work.

*The $\boldsymbol{e}$-Xtra logo stands for "electronic extra" and indicates that one supplementary figure is published online.

Accepted for publication 12 April 2015.

http://dx.doi.org/10.1094/PDIS-11-14-1142-RE

(C) 2016 The American Phytopathological Society has been grown in Xinjiang since more than 2,400 years ago (http://www.enread.com/news/sciandtech/55011.html). The region is considered to be a unique ER because the disease development pattern and $P$. striiformis f. sp. tritici races are different from those in other regions (Li and Zeng 2002). However, stripe rust research in Xinjiang has been limited for a number of reasons, including the fact that wheatgrowing areas are far away from the major stripe rust programs.

Systematic analysis of population structures of $P$. striiformis $\mathrm{f}$. $\mathrm{sp}$. tritici is important to identify factors affecting disease epidemics and develop management strategies. However, pertinent data regarding the pathogen population are not available for Xinjiang due to its particular geographic location and the lack of scientific expertise. Although this region is considered to be relatively independent from other regions in disease epidemiology, gene flow between the region and some other regions is still possible, although not clear. It is essential to understand the population structure of $P$. striiformis $\mathrm{f}$. sp. tritici in Xinjiang and the genetic relationships of the pathogen to populations in other regions, especially those in western China. Such information should provide the basis for developing effective strategies for control of the disease in the region and throughout the country.

Numerous studies using molecular markers demonstrated a high genetic diversity of $P$. striiformis f. sp. tritici in China, especially in southern Gansu (Duan et al. 2010; Lu et al. 2011; Mboup et al. 2009; Shan et al. 1998). By studying P. striiformis f. sp. tritici isolates from southern Gansu, Mboup et al. (2009) concluded that genetic recombination via the sexual cycle may occur in the Chinese population because of the relatively high genetic diversity compared with the $P$. striiformis f. sp. tritici populations in Europe and Australia. However, based on amplified fragment length polymorphism markers, Liu et al. (2011) reported that the $P$. striiformis f. sp. tritici population of Yunnan province in southwestern China is clonal because it has a relatively low level of diversity compared with the population in the Gansu province of northwestern China. Liang et al. (2013) compared the P. striiformis f. sp. tritici population structures of Gansu and Ningxia, also in northwestern China, and detected seasonal gene flow between the two regions. However, such information is very limited for Xinjiang. The objectives of this study were to (i) 
identify races and determine genetic diversity of the $P$. striiformis f. sp. tritici population in Xinjiang and (ii) determine the relationships of the $P$. striiformis f. sp. tritici population of the region with ER in western China.

\section{Materials and Methods}

Sample collection. During June to July 2013, diseased wheat leaves with uredinia of $P$. striiformis $\mathrm{f}$. sp. tritici were collected from Xinjiang and four other provinces or autonomous regions (Qinghai, Gansu, Ningxia, and Tibet) in western China (Table 1; Fig. 1). Five sites were chosen to collect stripe rust samples in each county and the sites were at least $10 \mathrm{~km}$ away from each other. On average, eight leaves, each treated as one sample, were collected from one site. About 40 samples were obtained from each county and considered as a subpopulation. The leaf samples were packaged in an absorbent paper bag and kept in a desiccator at $4^{\circ} \mathrm{C}$ for later use.

Multiplication and preservation of isolates. Prior to inoculation, the leaf samples were incubated at $10^{\circ} \mathrm{C}$ for $10 \mathrm{~h}$ in darkness on a wet absorbent paper in a petri dish to induce fresh urediniospore production. Ten-day-old seedlings of a susceptible cultivar, 'Mingxian 169', were inoculated with urediniospores from a single uredinium using a sterilized needle. Inoculated seedlings were incubated in a dew chamber at 10 to $13^{\circ} \mathrm{C}$ for $24 \mathrm{~h}$ in darkness, then transferred to a growth chamber programed at a light cycle of $13^{\circ} \mathrm{C}(8 \mathrm{~h}$ in darkness $)$ and $16^{\circ} \mathrm{C}$ (16 h of light). About 15 days after inoculation, inoculated leaves began to sporulate. Urediniospores were harvested and used to inoculate Mingxian 169 seedlings to increase urediniospores. When the inoculated seedlings were sporulating, urediniospores were collected with a clean tube and stored at $4^{\circ} \mathrm{C}$ for later use. Urediniospores from one uredium of a single leaf sample were treated as one isolate and only one isolate was obtained from one original sample.
Race identification. A set of 19 wheat genotypes (Table 2) were used to determine races of the obtained isolates. The differential genotypes were planted in $10-$ by-10-cm plastic pots filled with soil mixture, about five plants for each differential genotype. Approximately 10 days after planting, when the first leaves were fully expanded and the second leaves were about halfway emerged, seedlings were inoculated with fresh urediniospores mixed with talc at a 1:20 ratio. The inoculated plants were incubated in a dew chamber and grown in a growth chamber under the temperature and light conditions described above. Infection types were recorded based on a 0-to-9 scale (Chen et al. 2002; Line and Qayoum 1992) 18 to 20 days after inoculation. Infection types 0 to 5 were considered avirulent and 6 to 9 virulent. When infection type was not clear, the test on the differential genotypes was repeated.

DNA extraction. DNA of each isolate was extracted using a modified cetyltrimethylammonium bromide $(\mathrm{CTAB})$ protocol, as previously described (Zhan et al. 2012). Urediniospores $(20 \mathrm{mg}$ ) and $20 \mathrm{mg}$ of silica were placed in a 2-ml centrifuge tube, and $200 \mu \mathrm{l}$ of $2 \%$ CTAB (0.05 M CTAB, $0.14 \mathrm{M} \mathrm{NaCl}, 0.2 \mathrm{M}$ Tris-HCl [pH 8.0], and $20 \mathrm{mM}$ EDTA [pH 8.0]) was added. The mixture was milled on ice for about $1 \mathrm{~min}$ with a small drill. An additional $200 \mu \mathrm{l}$ of $2 \%$ $\mathrm{CTAB}$ and $5 \mu$ l of proteinase $\mathrm{K}$ were added to the tube, mixed gently, and incubated at $65^{\circ} \mathrm{C}$ for $2 \mathrm{~h}$. After addition of $700 \mu \mathrm{l}$ of phenol/chloroform/isoamyl alcohol (25:24:1, $\mathrm{pH}>7.8)$, the mixture was vortexed and then centrifuged for $10 \mathrm{~min}$ at $14,000 \mathrm{rpm}$ at $4^{\circ} \mathrm{C}$. The upper, aqueous phase was transferred into a fresh tube, $300 \mu l$ of chloroform was added, and the mixture was centrifuged for $10 \mathrm{~min}$ at $4^{\circ} \mathrm{C}$ at $12,000 \mathrm{rpm}$. The aqueous phase was transferred into a new tube, and $750 \mu 1$ of cool isopropanol was added. The mixture was incubated at $-20^{\circ} \mathrm{C}$ for $2 \mathrm{~h}$, then centrifuged for $30 \mathrm{~min}$ at $1,200 \mathrm{rpm}$. The precipitate was washed three times with $95 \%$ ethanol, dried, and

Table 1. Locations of Puccinia striiformis f. sp. tritici samples collected from western China

\begin{tabular}{|c|c|c|c|c|c|}
\hline ER, subregion ${ }^{a}$ & Location number & Location $^{b}$ & Latitude and longitude & Elevation (m) & Number of isolates \\
\hline R1 (Xinjiang) & $\ldots$ & $\ldots$ & $\ldots$ & $\ldots$ & 178 \\
\hline R1-1 & 1 & Urumqi & $\mathrm{N} 43^{\circ} 58.22^{\prime}$ E $87^{\circ} 09.41^{\prime}$ & 669 & 16 \\
\hline $\mathrm{R} 1-2$ & 2 & Xinyuan & $\mathrm{N} 43^{\circ} 23.66^{\prime} \mathrm{E} 83^{\circ} 16.70^{\prime}$ & 713 & 16 \\
\hline $\mathrm{R} 1-3$ & 3 & Tekesi & $\mathrm{N} 43^{\circ} 11.69^{\prime}$ E $81^{\circ} 50.96^{\prime}$ & 1,181 & 11 \\
\hline $\mathrm{R} 1-4$ & 4 & Changji & $\mathrm{N} 43^{\circ} 18.65^{\prime}$ E $86^{\circ} 0.01^{\prime}$ & 436 & 17 \\
\hline $\mathrm{R} 1-5$ & 5 & Yining & $\mathrm{N} 43^{\circ} 44.02^{\prime}$ E $81^{\circ} 50.99^{\prime}$ & 770 & 15 \\
\hline R1-6 & 6 & Dunmazha & $\mathrm{N} 43^{\circ} 54.66^{\prime}$ E $81^{\circ} 28.58^{\prime}$ & 690 & 30 \\
\hline R1-7 & 7 & Huocheng & $\mathrm{N} 44^{\circ} 18.65^{\prime} \mathrm{E} 86^{\circ} 0.01^{\prime}$ & 2,550 & 28 \\
\hline $\mathrm{R} 1-8$ & 8 & Nalati & $\mathrm{N} 43^{\circ} 23.28^{\prime} \mathrm{E} 83^{\circ} 50.25^{\prime}$ & 1,176 & 14 \\
\hline R1-9 & 9 & Tacheng & $\mathrm{N} 42^{\circ} 46.82^{\prime}$ E $82^{\circ} 57.63^{\prime}$ & 1,230 & 20 \\
\hline $\mathrm{R} 1-10$ & 10 & Hami & $\mathrm{N} 42^{\circ} 45.82^{\prime}$ E $93^{\circ} 26.47^{\prime}$ & 435 & 11 \\
\hline $\mathrm{R} 2$ & & & & $\ldots$ & 97 \\
\hline \multirow[t]{5}{*}{ R2GS } & 11 & Pingliang & $\mathrm{N} 34^{\circ} 41.03^{\prime}$ E $106^{\circ} 53.63^{\prime}$ & 1,595 & 8 \\
\hline & 12 & Wushan & $\mathrm{N} 34^{\circ} 38.21^{\prime}$ E $105^{\circ} 55.69^{\prime}$ & 1,661 & 9 \\
\hline & 13 & Pingnan & $\mathrm{N} 34^{\circ} 44.26^{\prime}$ E $105^{\circ} 30.28^{\prime}$ & 1,707 & 7 \\
\hline & 14 & Gangu & $\mathrm{N} 34^{\circ} 24.06^{\prime}$ E $105^{\circ} 10.48^{\prime}$ & 1,645 & 8 \\
\hline & 15 & Qinan & $\mathrm{N} 34^{\circ} 30.44^{\prime}$ E $105^{\circ} 12.35^{\prime}$ & 1,688 & 6 \\
\hline \multirow[t]{4}{*}{$\mathrm{R} 2 \mathrm{NX}$} & 16 & Jingyuan & $\mathrm{N} 35^{\circ} 20.47^{\prime}$ E $106^{\circ} 45.58^{\prime}$ & 1,711 & 10 \\
\hline & 17 & Longde & $\mathrm{N} 35^{\circ} 22.48^{\prime}$ E $106^{\circ} 47.32^{\prime}$ & 1,692 & 9 \\
\hline & 18 & Guyuan & $\mathrm{N} 35^{\circ} 11.78^{\prime}$ E $106^{\circ} 33.49^{\prime}$ & 1,608 & 9 \\
\hline & 19 & Pengyang & $\mathrm{N} 35^{\circ} 23.64^{\prime}$ E $106^{\circ} 51.11^{\prime}$ & 1,546 & 7 \\
\hline \multirow[t]{6}{*}{$\mathrm{R} 2 \mathrm{QH}$} & 20 & Tongde & $\mathrm{N} 35^{\circ} 14.12^{\prime}$ E $100^{\circ} 27.32^{\prime}$ & 2,979 & 5 \\
\hline & 21 & Huangzhong & $\mathrm{N} 36^{\circ} 27.31^{\prime}$ E $101^{\circ} 36.06^{\prime}$ & 2,668 & 4 \\
\hline & 22 & Datong & N $37^{\circ} 25.18^{\prime}$ E $101^{\circ} 39.18^{\prime}$ & 2,765 & 5 \\
\hline & 23 & Guide & $\mathrm{N} 35^{\circ} 59.31^{\prime}$ E $101^{\circ} 21.30^{\prime}$ & 2,409 & 3 \\
\hline & 24 & Huzhu & $\mathrm{N} 36^{\circ} 58.44^{\prime}$ E $101^{\circ} 52.35^{\prime}$ & 2,814 & 3 \\
\hline & 25 & Xinghai & $\mathrm{N} 35^{\circ} 36.11^{\prime} \mathrm{E} 101^{\circ} 54.54^{\prime}$ & 2,859 & 4 \\
\hline \multirow[t]{4}{*}{ R3 (Tibet) } & $\ldots$ & $\ldots$ & $\ldots$ & $\ldots$ & 33 \\
\hline & 26 & Linzhi & $\mathrm{N} 29^{\circ} 38.56^{\prime}$ E $94^{\circ} 41.46^{\prime}$ & 2,938 & 13 \\
\hline & 27 & Changdu & $\mathrm{N} 31^{\circ} 14.30^{\prime} \mathrm{E} 97^{\circ} 18.55^{\prime}$ & 3,174 & 10 \\
\hline & 28 & Shannan & $\mathrm{N} 29^{\circ} 22.90^{\prime}$ E $91^{\circ} 75.06^{\prime}$ & 3,056 & 10 \\
\hline Total & $\ldots$ & $\ldots$ & $\ldots$ & $\ldots$ & 308 \\
\hline
\end{tabular}

${ }^{\text {a }}$ ER = epidemiological regions; R1 = ER 1, covering Xinjiang; R2 = ER 2, covering Gansu (GS), Ningxia (NX), and Qinghai (QH) provinces; and R3 = ER 3, covering Tibet.

b According to the geographical and wheat production areas, subregions denote counties (locations) in R1 and R3 and provinces in R2. 
dissolved in $50 \mu \mathrm{l}$ of $1 \times$ Tris-EDTA buffer. DNA concentration was determined with an ND-1000 spectrophotometer (Bio-Rad), then diluted with double-distilled (dd) $\mathrm{H}_{2} \mathrm{O}$ to $50 \mathrm{ng} / \mu \mathrm{l}$ for later polymerase chain reaction (PCR) amplification.

Simple-sequence repeat primers, PCR amplification, and electrophoresis. Fifteen pairs of simple-sequence repeat (SSR) primers were used to amplify DNA. Among the primers, RJ3 and RJ20 were described by Enjalbert et al. (2002); RJ3 N and RJ13 N were described by Bahri et al. (2009); CPS01, CPS08, CPS09, CPS13, CPS27, and CPS36 were designed by Chen et al. (2009a); and PstP03, PstP06, PstP08, PstP23, and PstP42 were described by Cheng et al. (2012). PCR amplification was in a $25-\mu l$ volume comprising $2.0 \mu \mathrm{l}$ of DNA $(50 \mathrm{ng} / \mu \mathrm{l}), 2.5 \mu \mathrm{l}$ of $10 \times$ reaction buffer $\left(\mathrm{Mg}^{2+}\right.$ free), $2.0 \mu \mathrm{l}$ of $\mathrm{Mg}^{2+}(25 \mathrm{mM}), 2.0 \mu \mathrm{l}$ of dNTP $(2.5 \mathrm{mM}), 1 \mu \mathrm{l}$ of each primer $(10 \mathrm{mM}), 0.2 \mu \mathrm{l}$ of Taq DNA polymerase $(5 \mathrm{U} / \mu \mathrm{l}$; $\mathrm{TaKaRa}$ ), and $14.3 \mu \mathrm{l}$ of $\mathrm{ddH}_{2} \mathrm{O}$. PCR was carried out under the following conditions: initial denaturation at $94^{\circ} \mathrm{C}$ for $4 \mathrm{~min} ; 10$ cycles of $94^{\circ} \mathrm{C}$ for $45 \mathrm{~s}$ of denaturation, $64^{\circ} \mathrm{C}$ for $45 \mathrm{~s}$ with a $1^{\circ} \mathrm{C}$ decrease per cycle of annealing, and $72^{\circ} \mathrm{C}$ for $45 \mathrm{~s}$ of extension; 25 cycles of $94^{\circ} \mathrm{C}$ for $45 \mathrm{~s}$ of denaturation, $54^{\circ} \mathrm{C}$ for $45 \mathrm{~s}$ of annealing, and $72^{\circ} \mathrm{C}$ for $45 \mathrm{~s}$ of extension; and $72^{\circ} \mathrm{C}$ for $10 \mathrm{~min}$ of final extension. After amplification, $5 \mu \mathrm{l}$ of $6 \times$ formamide loading buffer was added to each product and denatured at $95^{\circ} \mathrm{C}$ for $5 \mathrm{~min}$. Denatured PCR product $(5 \mu \mathrm{l})$ was used to detect polymorphisms in a $6 \%$ denaturing polyacrylamide gel, and $4 \mu \mathrm{l}$ of DNA marker was used in each gel to estimate the size of SSR bands. Gel preparation, electrophoresis, and silver staining were done as described by Chen et al. (1998). The gel was washed three times with distilled water after electrophoresis, then stained in $0.1 \% \mathrm{AgNO}_{3}$ solution for $10 \mathrm{~min}$ and washed in distilled water for $10 \mathrm{~s}$. Gels were developed in $1.6 \% \mathrm{NaOH}$ solution containing $0.1 \%$ formaldehyde until the DNA bands were visible. The gel was incubated in $0.75 \% \mathrm{Na}_{2} \mathrm{CO}_{3}$ for $1 \mathrm{~min}$, washed for $5 \mathrm{~min}$, and photographed under UV light.

Data analyses. The virulence frequency for each of the provinces or autonomous regions, and also for each of the three ER (Xinjiang; Tibet; and Qinghai, Gansu, and Ningxia in combination; Fig. 1) was calculated using the Virulence Analysis Tools program (Kosman and Leonard 2007). The differences in virulence frequency among the provinces or ER were tested by a $\chi^{2}$ test based on the maximumlikelihood test. To determine the relationships among the populations, an unweighted pair-group method with arithmetic means (UPGMA) tree based on Nei's genetic distance (Nei 1972) was

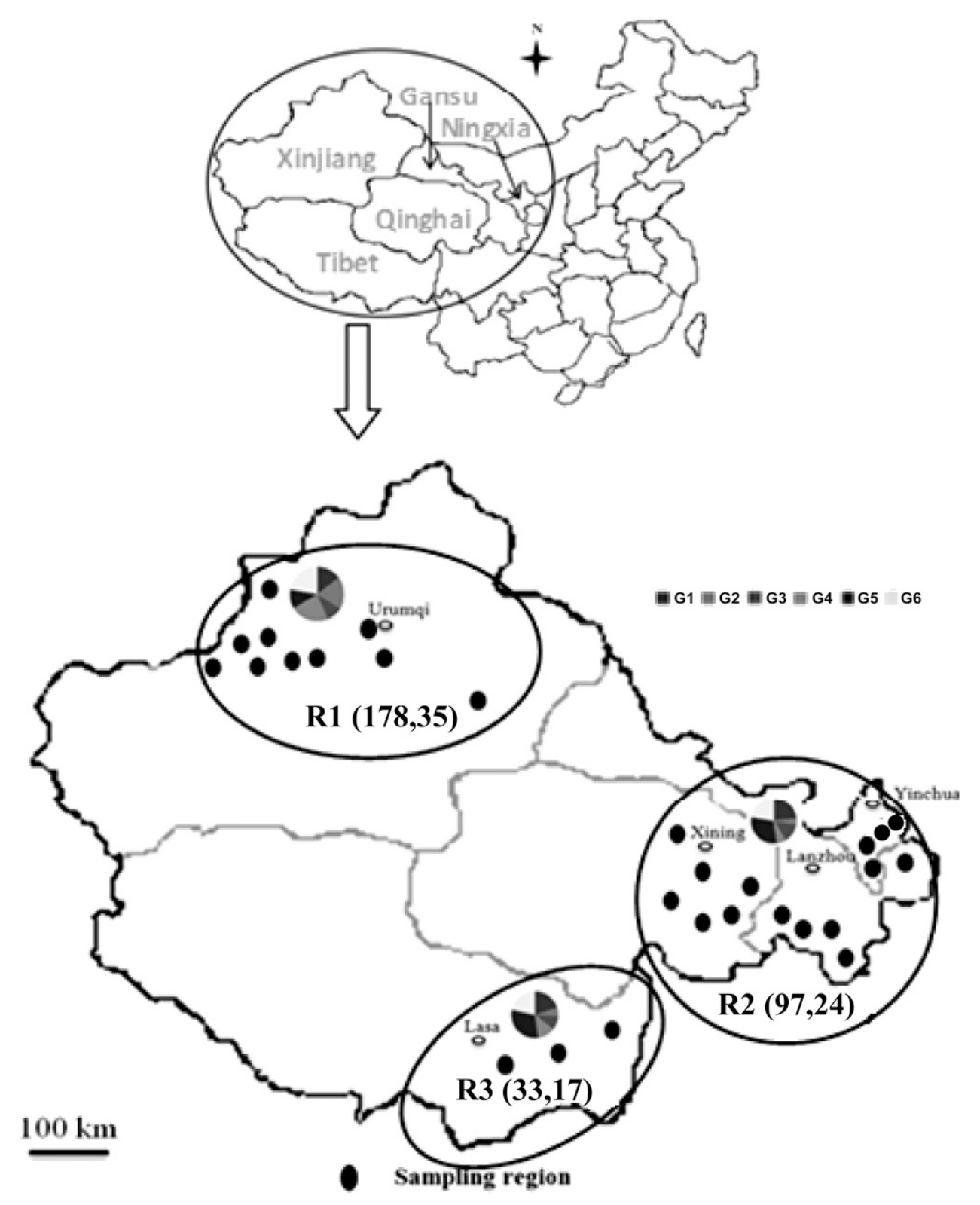

Fig. 1. Locations of stripe rust sampling and epidemiological regions (R). Numbers of isolates and races are given in the parentheses after each region. 
constructed with the POWERMARKER software, v3.25. A phylogenetic tree was established using software FigTree, v1.3.1 (Liu and Muse 2005) from the distance matrix generated by the Powermarker (Rambaut and Drummond 2010) and 1,000 bootstrap replications.

Genetic diversity was estimated using the observed number of alleles (Na), effective number of alleles $(\mathrm{Ne})$, number of polymorphic loci $(\mathrm{Np})$, percentage of polymorphic loci $(P)$, Shannon's information index $(I)$, expected heterozygosity $(\mathrm{He})$, and observed heterozygosity $(\mathrm{Ho})$, which was calculated using POPGENE software, v1.31 (Yeh et al. 1997). Population subdivision was analyzed through the model-based Bayesian analyses implemented in the STRUCTURE 2.2 software (Pritchard et al. 2000). The software assigns multilocus genotypes into clusters while minimizing the Hardy-Weinberg disequilibrium and gametic phase disequilibrium between loci within clusters (Pritchard et al. 2000).

The hypothesis of nondifferentiation among populations from the five provinces was tested by comparing the observed $\theta$ value based on the molecular marker data using MULTILOCUS v1.3 (Agapow and Burt 2001). To partition genetic variations within and among populations, analysis of molecular variance (AMOVA) was performed using GenAlEx 6.5 software (Peakall and Smouse 2006).

\section{Results}

$\boldsymbol{P}$. striiformis f. sp. tritici races and frequencies. In Xinjiang (region 1 [R1]), 27 previously known races and 8 unknown races were identified (Table 3 ). The most predominant race was HY46-8 (33.71\%), followed by HY46-6 (9.55\%), CYR32 (7.87\%), CYR20 (6.18\%), New-2 (4.49\%), and New-3 (3.37\%). All remaining races had frequencies below 3.00\%. In ER 2 (R2), including Qinghai, Gansu, and Ningxia provinces, 18 previously known races and 6 unknown races were identified (Table 3). CYR32 (26.8\%) was the most predominant race, followed by CYR33 (18.54\%), V26-1 (9.27\%), V26-2 (6.19\%), Su11-7 (5.14\%), HY46-8 (4.13\%), Lov13-3 (3.08\%), Lov13-5 (3.08\%), and V26-3 (3.08\%). The remaining races had frequencies less than $3.00 \%$. In Tibet (region 3 [R3]), 14 previously known races and 3 unknown races were identified (Table 3 ). CYR25 was the most frequent race (18.18\%), followed by CYR19 (9.09\%), CYR20 (9.09\%), CYR21 (9.09\%), CYR23 (9.09\%), CYR24 (9.09\%), and Lov10-5 (6.06\%). The remaining 10 races each were detected with only one sample (3.03\%). Overall, 56 races, including 39 previously reported and 17 new races, were identified from the 308 isolates tested (Table 3). Race HY46-8 had the highest frequency (20.78\%), followed by CYR32 (12.99\%), CYR33 (6.82\%), and CYR20 (4.55\%) throughout all regions sampled. All remaining races had less than $3.00 \%$ frequencies.

Table 2. Wheat genotypes used to differentiate races of Puccinia striiformis f. sp. tritici in western China

\begin{tabular}{lll}
\hline Number & \multicolumn{1}{c}{ Wheat genotype } & \multicolumn{1}{c}{ Yr gene $^{\mathbf{a}}$} \\
\hline 1 & Trigo-Eureka & Yr6 \\
2 & Fulhard & Unknown \\
3 & Lutescens 128 & Unknown \\
4 & Mentana & Unknown \\
5 & Virgilio & YrVirl, YrVir2 \\
6 & Abbondanza & Unknown \\
7 & Early Premium & Unknown \\
8 & Funo & $Y r A,+$ \\
9 & Danish 1 & $Y r 3$ \\
10 & JubilejinaII & $Y r J u 1, Y r J u 2, Y r J u 3, Y r J u 4$ \\
11 & Fengchan 3 & $Y r 9,+$ \\
12 & Lovrin 13 & $Y r 1, Y r K y 1, Y r K y 2$ \\
13 & Kangyin 655 & $Y r S u$ \\
14 & Suwon 11 & Unknown \\
15 & Zhong 4 & $Y r 9$ \\
16 & Lovrin 10 & $Y r 3 b, Y r 4 b$ \\
17 & Hybrid 46 & $Y r 5$ \\
18 & Triticum spelta var. Album & $Y r 10, Y r 26$ \\
19 & Guinong22 & \\
\hline
\end{tabular}

a Refer to Wan et al. (2004) and Chen et al. (2009b) for the $Y r$ genes in the Chinese wheat differentials.
Old races with a narrower virulence spectrum, such as CYR17 CYR21, CYR23 - CYR27, and CYR29, were detected only in Xinjiang (R1) and/or Tibet (R3), but absent in R2 (Qinghai, Gansu, and Ningxia) (Table 3). The races virulent to Yr26 (V26-1, V26-2, and V26-3) were detected only in R2, but absent in R1 and R3 (Table 3; Fig. 2). More races were detected in R1 than either R2 or R3.

Virulence frequencies. The frequencies of virulence factors based on the differential genotypes in the three ER are shown in Figure 2. No virulences to differentials Zhong 4 (C15), with an unnamed resistance gene, and Triticum spelta var. Album (C18), with $Y r 5$, were detected in any of the regions. Virulence to Guinong 22 (C19) with $\operatorname{Yr} 26$ (= Yr24) was detected only in R2 at a frequency of $18.54 \%$. The Fulhard (C2) virulence was detected with $100 \%$ frequency in all three regions. The frequencies of virulences to Trigo Eureka (C1), Mentana (C4), Abbondanza (C6), Early Premium (C7), Funo (C8), and Fengchan 3 (C11) were not significantly different among the three regions $(P>0.05)$. The frequencies of virulences to the remaining differentials-Lutescens 128 (C3), Virgilio (C5), Danish 1 (C9), Jubilejina (C10), Lovrin 13 (C12), Kangyin 655 (C13), Suwon 11 (C14), Lovrin 10 (C16), and Hybrid 46 (C17)—differed significantly among the three regions $(P<0.01)$. When significantly different, the virulence frequency in R1 was generally lower than that in R2 but similar to that in R3, except virulences to Lovrin 13 (C12), Suwon 11 (C14), Lovrin 10 (C16), and Hybrid 46 (C17).

Molecular diversity. Using the 15 polymorphic SSR markers, 180 multilocus genotypes were identified from the 308 isolates tested and clustered into five molecular groups (MG). The relative distances among the five MG are shown in Figure 3 and more detailed genetic relationships of the 308 isolates are shown in Supplementary Figure $\mathrm{S} 1$. MG1 consisted of 91 isolates ( 54 from R1, 24 from R2, and 13 from R3); MG2 consisted of 11 isolates (10 from R1 and 1 from R3); MG3 consisted of 79 isolates (68 from R1, 9 from R2, and 2 from R3); MG4 consisted of only 3 isolates, all from R1; and MG5 consisted of 124 isolates ( 43 from R1, 63 from R2, and 18 from R3) (Fig. 3). Because all five MG contained isolates from Xinjiang (R1), the $P$. striiformis $\mathrm{f}$. sp. tritici population in this region had a higher genetic diversity than either Qinghai, Gansu, and Ningxia combined (R2) or Tibet (R3). The result is consistent with the higher number of races detected in Xinjiang.

Diversity parameters of the $P$. striiformis f. sp. tritici populations based on the SSR markers are shown in Table 4. The $\mathrm{Na}$ in each of the three ER populations was 2.00 and the $\mathrm{Ne}$ was the highest (1.91) in R1 and lowest (1.81) in R3. All 15 marker loci were polymorphic, as indicated by the consistent $N p(=15)$ in all three ER and also in all subregions. Shannon's I value was the highest in R1 (0.67) and the lowest in R3 among the three ER. The different subregions in R1 had relatively similar $I$ values, ranging from 0.58 to 0.63 ; whereas, in R2, the values had a wide range with 0.48 in R2NX (Ningxia) and 0.63 in R2GS (Gansu). $\mathrm{Ho}$ and $\mathrm{He}$ were similar among the three ER but more different among some of the subregions in both R1 and R2.

Differentiation among populations. The observed $\theta$ values revealed high genetic differentiation $(P<0.01)$ between the Xinjiang population (R1) and either of the other two populations (R2 and R3) (Table 5). UPGMA analysis based on Nei's genetic distance also suggested the existence of differentiation among the three populations (Fig. 4). Both the observed $\theta$ value and UPGMA analysis indicated that Xinjiang was a separate ER but relatively close to R2 (Gansu, Qinghai, and Ningxia) compared with R3 (Tibet).

When AMOVA of the SSR data were conducted for the individual populations of the three ER, R1 had the highest variation (9\%) and R3 had the lowest (0\%) among subpopulations (Table 6). The majority (91 to 99\%) of the entire genetic variation was observed within populations. When the data of the three ER were compared, genetic variation was primarily (98\%) from within populations and only $2 \%$ was from among populations.

\section{Discussion}

The dynamics of $P$. striiformis f. sp. tritici races in China has been monitored for more than 70 years (Chen et al. 2009b; Fang 1944), whereas the disease survey in Xinjiang has been sporadic, with a very 
Table 3. Races of Puccinia striiformis f. sp. tritici detected using the set of 19 Chinese wheat differentials and their frequencies in epidemiological regions (R1 to R3) in western China in 2013

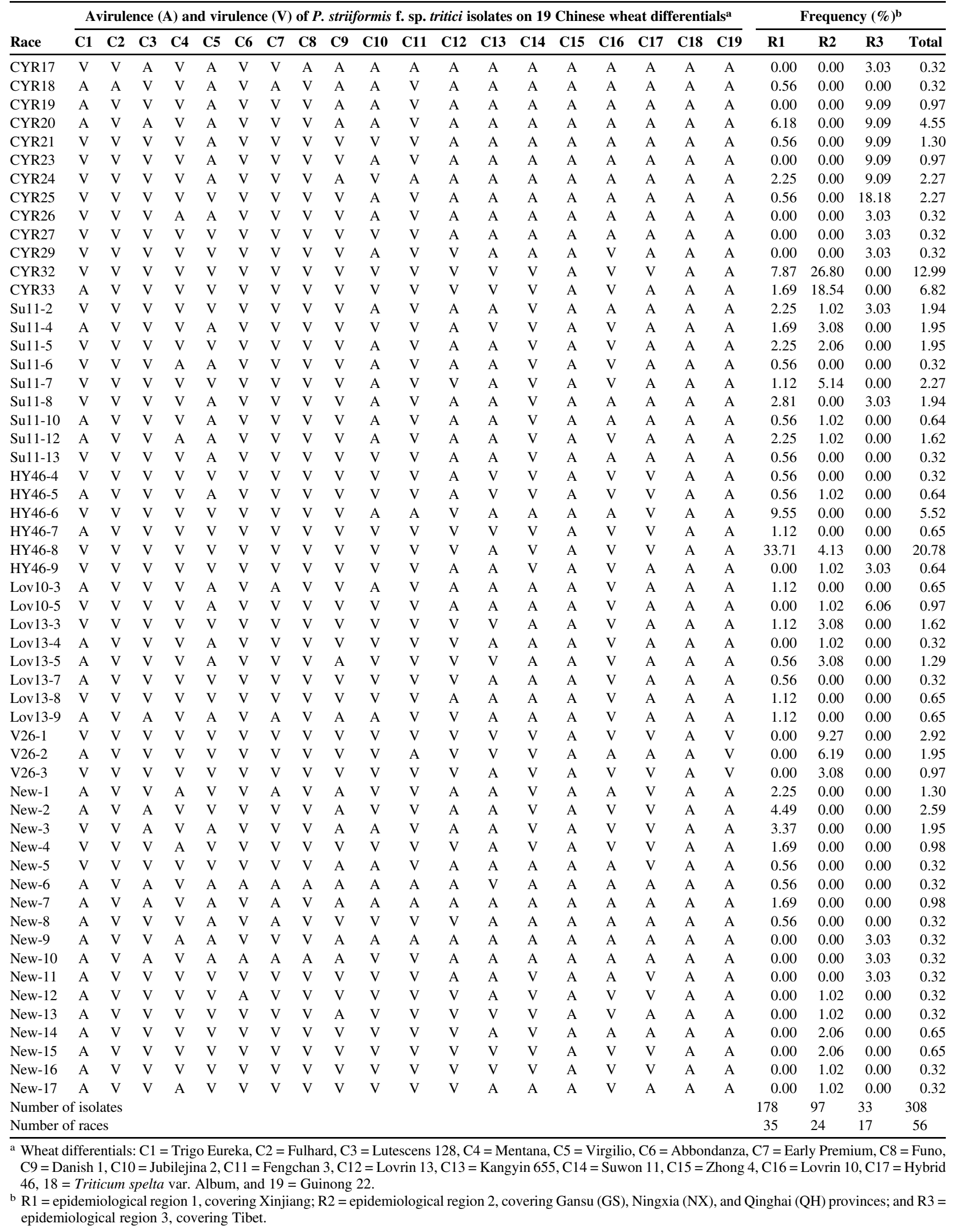


limited number of samples (Wang et al. 1963). Using both the virulence phenotyping and molecular genotyping approaches, the present study compared $P$. striiformis $\mathrm{f}$. sp. tritici populations in Xinjiang with adjacent provinces (Qinghai, Gansu, Ningxia, and Tibet) in western China. From the 178 isolates collected from Xinjiang, 35 races were identified, of which 27 were previously known and 8 were unknown. Both the total number of races and the number of new races identified in 2013 were the highest in the record of Xinjiang. Compared with the neighboring R2 (Qinghai, Gansu, and Ningxia), which is the most frequent stripe rust ER, and R3 (Tibet), the

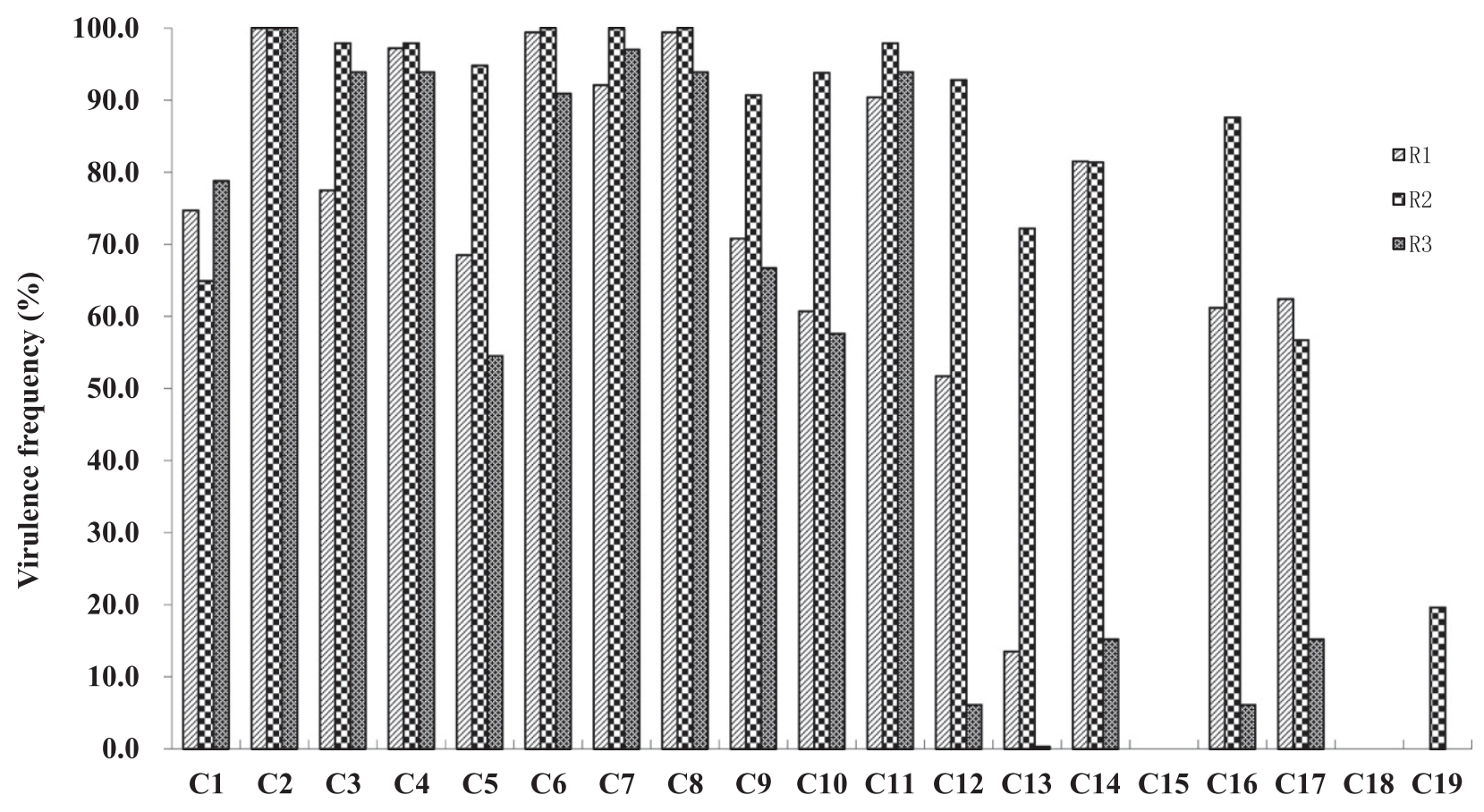

Chinese differentials

Fig. 2. Virulence frequencies of Puccinia striiformis f. sp. tritici in epidemiological regions $(\mathrm{R})$ in western China. Virulences were based on Chinese differentials: $\mathrm{C} 1=$ Trigo Eureka, $\mathrm{C} 2=$ Fulhard, $\mathrm{C} 3=$ Lutescens128, C4 = Mentana, C5 = Virgilio, C6 = Abbondanza, C7 = Early Premium, C8 = Funo, C9 = Danish 1, C10 = Jubilejina 2, C11 = Fengchan 3, C12 = Lovrin 13, C13 = Kangyin 655, C14 = Suwon 11, C15 = Zhong 4, C16 = Lovrin 10, C17 = Hybrid 46, $18=$ Triticum spelta var. Album, and $19=$ Guinong 22.

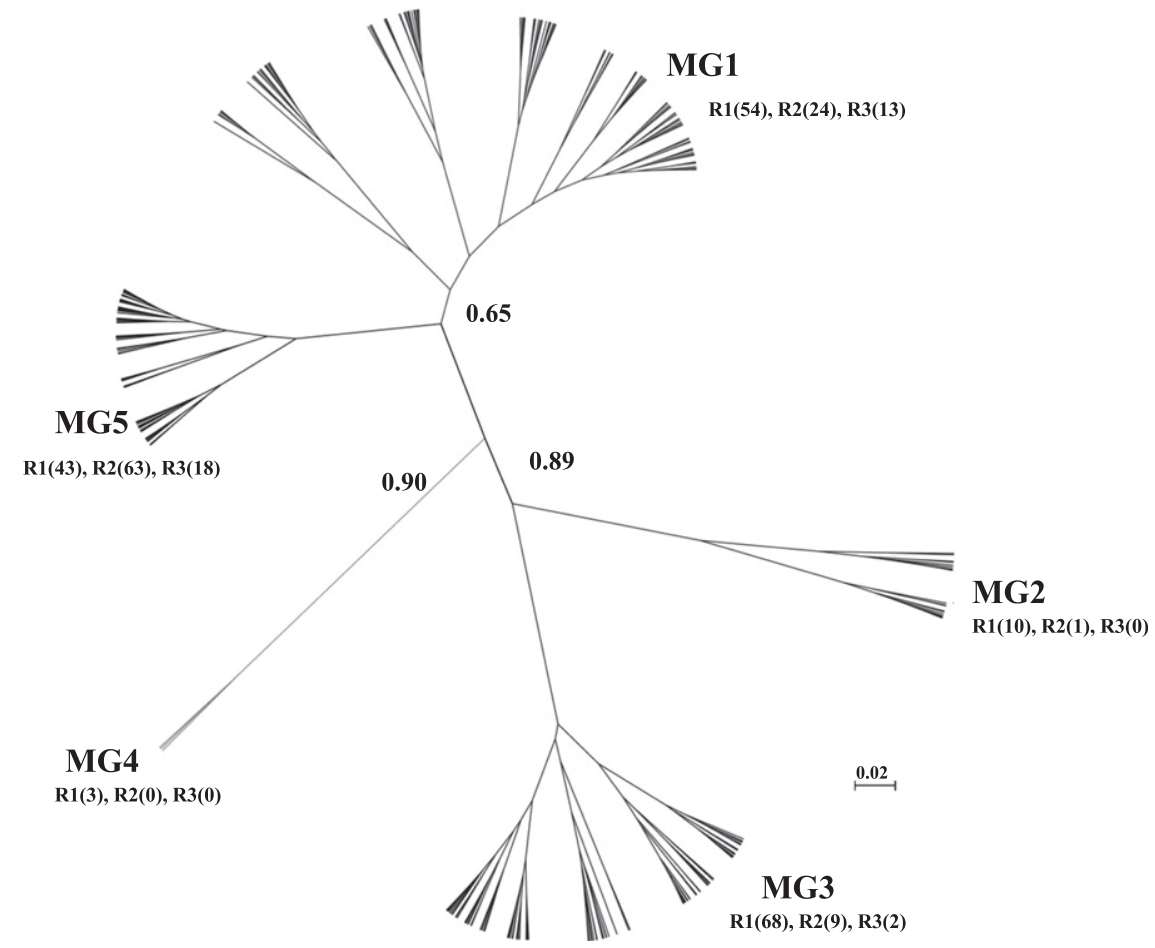

Fig. 3. Relationships of molecular groups (MG) of Puccinia striformis f. sp. tritici constructed using unweighted pair-group method with arithmetic means based on the simplesequence repeat data. The number of isolates for each epidemiological region $(R)$ is shown in parentheses. 
Table 4. Genetic diversity parameters based on simple sequence repeat (SSR) markers of Puccinia striiformis f. sp. tritici in epidemiological regions and subregions in western China

\begin{tabular}{cccccccc}
\hline & & \multicolumn{7}{c}{ Parameter $^{\mathbf{a}}$} \\
\cline { 3 - 8 } ER, subregion & $\boldsymbol{n}^{\mathbf{c}}$ & $\boldsymbol{N a}$ & $\boldsymbol{N e}$ & $\boldsymbol{N p}$ & $\boldsymbol{I}$ & $\boldsymbol{H o}$ & $\boldsymbol{H e}$ \\
\hline R1 & 178 & 2.00 & 1.91 & 15 & 0.67 & 0.48 & 0.47 \\
R1-1 & 16 & 2.00 & 1.77 & 15 & 0.61 & 0.43 & 0.55 \\
R1-2 & 16 & 2.00 & 1.81 & 15 & 0.63 & 0.59 & 0.55 \\
R1-3 & 11 & 2.00 & 1.85 & 15 & 0.64 & 0.57 & 0.53 \\
R1-4 & 17 & 2.00 & 1.88 & 15 & 0.66 & 0.52 & 0.48 \\
R1-5 & 15 & 2.00 & 1.69 & 15 & 0.59 & 0.43 & 0.41 \\
R1-6 & 30 & 2.00 & 1.70 & 15 & 0.58 & 0.43 & 0.40 \\
R1-7 & 28 & 2.00 & 1.75 & 15 & 0.61 & 0.45 & 0.43 \\
R1-8 & 14 & 2.00 & 1.76 & 15 & 0.61 & 0.50 & 0.44 \\
R1-9 & 20 & 2.00 & 1.76 & 15 & 0.60 & 0.46 & 0.44 \\
R1-10 & 11 & 2.00 & 1.69 & 15 & 0.57 & 0.41 & 0.41 \\
R2 & 97 & 2.00 & 1.83 & 15 & 0.64 & 0.46 & 0.45 \\
R2GS & 38 & 2.00 & 1.84 & 15 & 0.63 & 0.48 & 0.45 \\
R2NX & 35 & 1.93 & 1.57 & 15 & 0.48 & 0.37 & 0.34 \\
R2QH & 24 & 2.00 & 1.78 & 15 & 0.61 & 0.48 & 0.43 \\
R3 & 33 & 2.00 & 1.81 & 15 & 0.62 & 0.47 & 0.45 \\
\hline
\end{tabular}

${ }^{\text {a }} \mathrm{Na}=$ observed number of alleles, $\mathrm{Ne}=$ effective number of alleles, $\mathrm{Np}=$ the number of polymorphic loci, $I=$ Shannon's information index, $H o=$ observed heterozygosity, and $\mathrm{He}=$ expected heterozygosity.

b $\mathrm{ER}=$ epidemiological regions; R1 = ER 1, covering Xinjiang; R2 = ER 2, covering Gansu (GS), Ningxia (NX), and Qinghai $(\mathrm{QH})$ provinces; and R3 = ER 3 , covering Tibet. According to the geographical and wheat production areas, subregions denote counties (locations) in R1 and R3 and provinces in R2.

c Number of isolates.

Table 5. Estimates of genetic differentiation $\theta$ and $P$ values based on the simple-sequence repeat marker data of Puccinia striiformis f. sp. tritici isolates collected from three epidemiological regions (R1 to R2) and the subregions in R2 (R2GS, R2NX, and R2QH) in western China ${ }^{a}$

\begin{tabular}{lcccccr}
\hline & \multicolumn{7}{c}{$\boldsymbol{\theta}$ (above the diagonal line) and $\boldsymbol{P}$ (below) } \\
ER or subregions \\
\cline { 2 - 8 } ER, subregion & R1 & R2 & R3 & R2GS & R2NX & R2QH \\
\hline R1 & $* * *$ & 0.04 & 0.05 & 0.05 & 0.04 & 0.07 \\
R2 & $<0.01$ & $* * *$ & 0.03 & $<\mathbf{0 . 0 1}$ & $<\mathbf{0 . 0 1}$ & $-\mathbf{0 . 0 1}$ \\
R3 & $<0.01$ & $<0.01$ & $* * *$ & 0.03 & 0.05 & 0.05 \\
R2GS & $<0.01$ & $\mathbf{0 . 3 3}$ & 0.03 & $* * *$ & 0.05 & 0.02 \\
R2NX & $<0.01$ & $\mathbf{0 . 2 8}$ & $<0.01$ & $<0.01$ & $* * *$ & 0.02 \\
R2QH & $<0.01$ & $\mathbf{0 . 8 3}$ & $<0.01$ & 0.10 & 0.03 & $* * *$ \\
\hline
\end{tabular}

a $\mathrm{ER}$ = epidemiological region; R1 = ER 1, covering Xinjiang; R2 = ER 2, covering Gansu (GS), Ningxia (NX), and Qinghai $(\mathrm{QH})$ provinces; and R3 = ER 3, covering Tibet. According to the geographical and wheat production areas, subregions denote counties (locations) in R1 and R3 and provinces in R2.

b Genetic differentiation $\theta$ values were generated by bootstrapping over loci using 1,000 replications. A $P$ value $<0.05$ indicates a significant differentiation among populations.
$P$. striiformis $\mathrm{f}$. sp. tritici race number was relatively high, indicating the high virulence diversity in Xinjiang. Such a high number of races is probably due to the large geographic area, the widespread severe stripe rust, and our special effort for collecting stripe rust in 2013 in Xinjiang. Compared with Xinjiang, the other two ER had relatively low stripe rust in 2013. More races were detected in R1 (Xinjiang) than either R2 (Qinghai, Gansu, and Ningxia combined) or R3 (Tibet), probably due to the larger number of samples collected from the relatively large region. The result indicates that the importance of stripe rust in Xinjiang should not be ignored and more effort should be taken to monitor and manage stripe rust in this region.

The previously reported races detected in this study included many old Chinese races, such as CYR18, CYR20, CYR21, CYR24, and CYR25, which were detected in high frequencies in Xinjiang but hardly detected in other regions in China; and some current predominant races, such as CYR32. Interestingly, some recently emerging races such as those virulent to $\mathrm{Yr} 26$ were not detected in Xinjiang. These results indicate that the $P$. striiformis $\mathrm{f}$. sp. tritici population in Xinjiang comprises historical and recent populations, and race changes appear to be slower than and behind changes in inland regions. The results also indicate that the $P$. striiformis f. sp. tritici population in Xinjiang is related to but appears different from those in other regions of China, because the race dynamics are lagging behind. This phenomenon is caused by the different effects of urediniospores spreading between Xinjiang and other neighboring regions, and isolation by high mountains and big deserts. Sharing wheat germplasm with inland regions and the continued growth of some old wheat cultivars in the region may have also contributed to the similar and different race compositions. In Xinjiang, wheat is grown mostly in two basins (Junggar Basin in the north and Tarim Basin in the south) and surrounded by three mountains (Altai Mountain in the north, Kunlun Mountain in the south, and Tianshan Mountain in the center). Wheat cultivars grown in Xinjiang include local cultivars and cultivars introduced from inland regions. The high climatic and ecological diversity plus diverse wheat cultivars may have shaped the highly diverse $P$. striiformis $\mathrm{f}$. sp. tritici population in the region.

All of the eight new races identified in Xinjiang had low frequencies, indicating that they could either have evaded sampling in previous studies or developed recently in the $P$. striiformis f. sp. tritici population. Interestingly, these races were not detected in other regions, and none of the other nine new races detected in R2 and R3 were detected in Xinjiang. These results indicate that new races not only first appear in "hotspot" regions such as R2, which has been traditionally considered as the birthplace of new races (Chen et al. 2009b; Li and Zeng 2002; Wan et al. 2004), but also are produced in "non-hotspot" regions such as Xinjiang. Further work should be conducted to monitor the frequency and distribution changes of the new races in Xinjiang as well as in other regions.

Comparing the virulence structures among the three populations, we found that races V26-1, V26-2, and V-26-3, which are virulent on Guinong 22 with $\operatorname{Yr} 26$ (Liu et al. 2010), were present in Gansu,

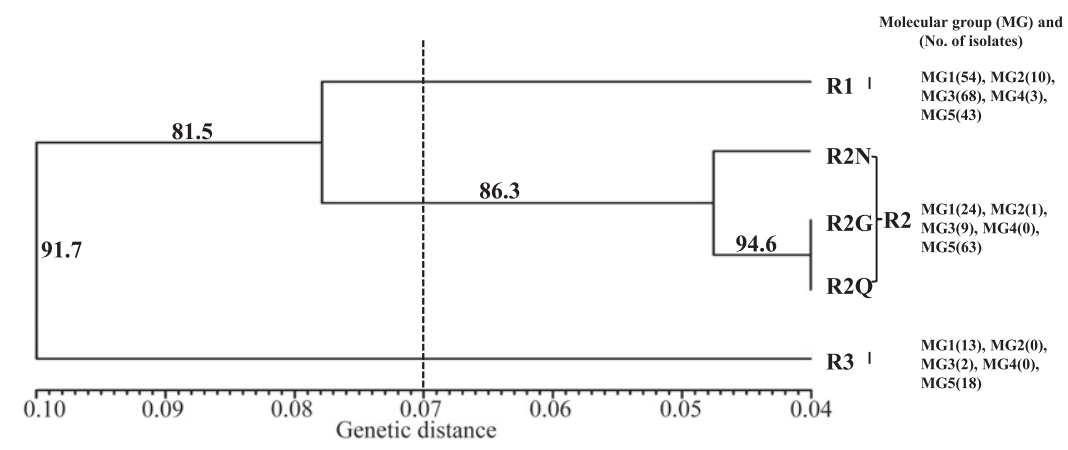

Fig. 4. Relationships of the Puccinia striiformis f. sp. tritici populations in epidemiological regions based on Nei's genetic distances estimated using simple-sequence repeat markers. The number of isolates for each molecular group (MG) is shown in parentheses. 
Ningxia, and Qinghai but absent in Xinjiang and Tibet. Although the frequency of the $\operatorname{Yr} 26$ virulence is low, it has been found on several continents (Ali et al. 2014; Sharma-Poudyal et al. 2013). Because the Yr26 virulence has not been found in Xinjiang and Tibet, cultivars with $\operatorname{Yr} 26$ may still be grown; however, monitoring the virulence should be continually conducted in these regions. Once the virulence appears, cultivars with only $Y r 26$ should be withdrawn from production.

The molecular data showed that the genetic diversity of the $P$. striiformis f. sp. tritici population in Xinjiang is higher than in the other two ER. The number of molecular genotypes in Xinjiang was higher than the other two regions, and the genotypes were distributed in all five MG. In contrast, the genotypes of R2 (Qinghai, Gansu, and Ningxia) were in four of the five MG and those of R3 (Tibet) were in three of the four MG. MG4 was unique to and MG2 almost restricted to Xinjiang. The various diversity indices were generally higher in Xinjiang than in either of the other two regions. Furthermore, the variation among subpopulations was higher in Xinjiang than those in the other two ER. The clustering results and $\theta$ values showed significant differentiation between Xinjiang and either of the two other regions. Both virulence and molecular data showed that the $P$. striiformis $\mathrm{f}$. sp. tritici population in Xinjiang is more diverse than in other ER.

Virulence tests and molecular markers are two effective labeling systems to study $P$. striiformis f. sp. tritici populations. Several studies (Chen et al. 1993; Pasquali et al. 2010; Zhan et al. 2012) have reported that virulence and molecular marker data are either not significantly correlated or have low correlations. In the present study, we identified a total of 56 races using 19 wheat differentials and 180 multilocus genotypes using 15 SSR primer pairs from the 308 isolates. The race/isolate ratio is 1:5.5, while the genotype/isolate ratio is $1: 1.7$. The correlation coefficient between the virulence data and the SSR marker data were very low $(r=0.03, P=0.95)$. One of the possible reasons is that the molecular markers used in the present study are neutral and virulences are under the strong host selection. We found that many isolates were identified as the race but as different marker genotypes. For example, isolates R1-25 (MG3), R1-54 (MG1), R1-109 (MG5) and R1-136 (MG2) were all identified as CYR32 but were separated into four MG. Similarly, isolates of the same marker genotype can be of different races. For instance, isolates

Table 6. Analysis of molecular variance (AMOVA) based on the simplesequence repeat marker data of Puccinia striiformis $\mathrm{f}$. sp. tritici isolates collected from three epidemiological regions (R1 to R3) in western China

\begin{tabular}{lrrrrrc}
\hline & \multicolumn{7}{c}{ AMOVA parameter or value } \\
\cline { 2 - 7 } Source of variation & \\
\cline { 2 - 7 } & $\boldsymbol{d} \boldsymbol{f}$ & \multicolumn{1}{c}{ SS } & VC & PV $(\%)$ & $\boldsymbol{F}$ & $\boldsymbol{P}$ \\
\hline R1 Among subpopulations & 9 & 145.89 & 16.21 & 9 & 0.38 & $<0.01$ \\
$\quad$ & 168 & 647.00 & 3.64 & 91 & 3.64 & $<0.01$ \\
$\quad$ Within population & 177 & 792.89 & 19.85 & 100 & 4.02 & $\ldots$ \\
$\quad$ Total & & & & & & \\
R2 & 2 & 9.51 & 4.58 & 1 & 0.02 & $<0.01$ \\
$\quad$ Among subpopulations & 94 & 334.50 & 3.45 & 99 & 3.45 & $<0.01$ \\
$\quad$ Within population & 96 & 344.01 & 8.03 & 100 & 3.47 & $\ldots$ \\
$\quad$ Total & & & & & & \\
R3 & 2 & 5.56 & 2.78 & 0 & 0.01 & $<0.01$ \\
$\quad$ Among subpopulations & 30 & 116.00 & 3.52 & 100 & 3.51 & $<0.01$ \\
$\quad$ Within population & 32 & 121.56 & 6.30 & 100 & 3.52 & $\ldots$ \\
$\quad$ Total & & & & & & \\
Comparison of R1, R2, & & & & & & \\
$\quad$ and R3 & 2 & 37.30 & 18.64 & 2 & 0.09 & $<0.01$ \\
$\quad$ Among subpopulations & 305 & 1097.50 & 3.56 & 98 & 3.57 & $<0.01$ \\
$\quad$ Within population & 307 & 1134.80 & 22.20 & 100 & 4.66 & $\ldots$ \\
$\quad$ Total &
\end{tabular}

a Abbreviations: $d f=$ degree of freedom, $\mathrm{SS}=$ sum of squares, $\mathrm{VC}=$ variance components, and $\mathrm{PV}=$ percentage of variation. $P$ values are based on 1,000 permutations.

b $\mathrm{R} 1$ = epidemiological region 1, covering Xinjiang; R2 = epidemiological region 2, covering Gansu (GS), Ningxia (NX), and Qinghai (QH) provinces; and R3 = epidemiological region 3, covering Tibet.
R1-38 (race CYR32), R1-40 (race Su11-2), and R1-80 (race Su11-12) were identified as different races but were almost identical and grouped in MG3. Because of the very low correlation coefficient, we were unable to relate any of the MG to a race group. To tag a race or race group, more markers or other types of markers need to be developed. The data suggest that a $P$. striiformis $\mathrm{f}$. sp. tritici race may consist of genetically different isolates. Almost no correlation between the virulence and marker data indicates that both virulence phenotyping and marker genotyping are needed to study $P$. striiformis f. sp. tritici populations for a better understanding of the population structure and evolutionary mechanisms, as well as to provide useful virulence data for developing wheat cultivars with effective resistance.

China is one of the largest relatively independent wheat stripe rust ER in the world (Stubbs 1985) but considerable controversy surrounds the regional classification of epidemics in China. The eastern and southern regions of Gansu Province and the northwestern region of Sichuan Province were considered as key ER for P. striiformis f. sp. tritici (Li and Zeng 2002). Previous studies reported that race evolution in the Xinjiang and Tibet populations lagged behind that on the mainland (Wu et al. 1993) but the reasons for this phenomenon were not clear. Through virulence analysis of 19 Chinese differentials, Hu et al. (2012) considered Tibet to be the third center of inoculum source and genetic variation for the stripe rust pathogen in China. In the present study, we also found that the Xinjiang population has features similar to the population in Tibet, where old races coexist with current, common ones. On the other hand, the predominant races and their frequencies are different in these two regions and also different from R2 (Qinghai, Gansu, and Ningxia). For instance, the prevalent races in Xinjiang are HY46-8, HY46-6, CYR32, and CYR20, whereas in Tibet they are CYR25, CYR24, CYR23, and CYR19. All of the evidence supported the conclusion that Xinjing should be considered an important ER, parallel to other regions in China, and that the region should receive similar attention in stripe rust monitoring and control.

As expected, we found that ER based on administrative or geographic divisions are not sufficient for epidemiological studies of wheat stripe rust in China. Because there are no borders for urediniospore spread between provinces, countries, and even continents, ER should be defined based on climates, natural barriers such as high mountains and large deserts, and cropping systems, just as ER have been established in North America (Chen 2005; Line and Qayoum 1992; Wan and Chen 2014). Thus, we divided the five provinces (Xinjiang, Qinghai, Gansu, Ningxia, and Tibet) into three ER. Analyses of the $P$. striiformis $\mathrm{f}$. sp. tritici isolates according to the three regions provided more reasonable comparisons and more useful information for stripe rust management, as discussed above.

Wheat-growing regions of Xinjiang cover vast but not continuous areas along the Altai, Tianshan, and Kunlun mountains, which influence the spread of $P$. striiformis $\mathrm{f}$. sp. tritici urediniospores and make the $P$. striiformis f. sp. tritici population in Xinjiang complex. Further studies are needed to fully understand the diverse phenotypes and genotypes of $P$. striiformis f. sp. tritici and develop more wheat cultivars with a high level and durable resistance to stripe rust in Xinjiang. Because Xinjiang is adjacent to Central Asia, the question of whether the $P$. striiformis $\mathrm{f}$. sp. tritici urediniospores may spread between Xinjiang and the central Asian countries should be studied. Sources of oversummering and overwintering, the incidence of epidemics, comprehensive and systematic surveys of the P. striiformis f. sp. tritici population in Xinjiang, as well as the influence of wheat cultivation on the trajectory of disease spread need to be studied in order to improve control of the disease in Xinjiang and other regions.

\section{Acknowledgments}

This work was supported by the National Key Basic Research Program of China (2013CB127700), Special Fund for Agro-scientific Research in the Public Interest (number 201303023), the earmarked fund for Modern Agroindustry Technology Research System (number CARS-3-1-11), the Nature Science Foundation of China (31371882), and the 111 Project from the Ministry of Education of China (number B07049). We thank L. D. Dunkle, Crop Production and Pest Control Research Unit, USDA-ARS, Purdue University, for reviewing the manuscript. 


\section{Literature Cited}

Agapow, P. M., and Burt, A. 2001. Indices of multilocus linkage disequilibrium. Mol. Ecol. Notes 1:101-102.

Ali, S., Gladieux, P., Leconte, M., Gautier, A., Justesen, A. F., Hovmoller, M. S., Enjalbert, J., and De Vallavieille-Pope, C. 2014. Origin, migration routes and worldwide population genetic structure of the wheat yellow rust pathogen Puccinia striiformis f. sp. tritici. PLoS Pathog. 10:e1003903.

Bahri, B., Leconte, M., de Vallavieille-Pope, C., and Enjalbert, J. 2009. Isolation of ten microsatellite loci in an EST library of the phytopathogenic fungus Puccinia striiformis f. sp. tritici. Conserv. Genet. 10:1425-1428.

Chen, C. Q., Zheng, W. M., Huang, L. L., Lu, N. H., and Kang, Z. S. 2009a. Isolation of microsatellite loci from expressed sequence tags (ESTs) library of Puccinia striiformis f. sp. tritici. Mol. Ecol. Resour. 9:236-238.

Chen, W. Q., Wellings, C., Chen, X. M., Kang, Z. S., and Liu, T. G. 2014. Wheat stripe (yellow) rust caused by Puccinia striiformis f. sp. tritici. Mol. Plant Pathol. 15:433-446.

Chen, W. Q., Wu, L. R., Liu, T. G., Xu, S. C., Jin, S. L., Peng, Y. L., and Wang, B. T. 2009b. Race dynamics, diversity, and virulence evolution in Puccinia striiformis f. sp. tritici, the causal agent of wheat stripe rust in China from 2003 to 2007. Plant Dis. 93:1093-1101.

Chen, X. M. 2005. Epidemiology and control of stripe rust [Puccinia striiformis f. sp. tritici] on wheat. Can. J. Plant Pathol. 27:314-337.

Chen, X. M., Line, R. F., and Leung, H. 1993. Relationship between virulence variation and DNA polymorphism in Puccinia striiformis. Phytopathology 83:1489-1497.

Chen, X. M., Line, R. F., and Leung, H. 1998. Genome scanning for resistancegene analogs in race, barley and wheat by high resolution electrophoresis. Theor. Appl. Genet. 97:345-355.

Chen, X. M., Moore, M. K., Milus, E. A., Long, D. L., Line, R. F., Marshall, D., and Jackson, L. 2002. Wheat stripe rust epidemics and races of Puccinia striiformis f. sp. tritici in the United States in 2000. Plant Dis. 86:39-46.

Cheng, P., Chen, X. M., Xu, L. S., and See, D. R. 2012. Development and characterization of expressed sequence tag-derived microsatellite markers for the wheat stripe rust fungus Puccinia striiformis f. sp. tritici. Online publication. Mol. Ecol. Res. http://tomato.biol.trinity.edu/manuscripts/12-4/mer-11-0397.pdf

Duan, X., Tellier, A., Wan, A., Leconte, M., de Vallavieille-Pope, C., and Enjalbert, J. 2010. Puccinia striiformis f. sp. tritici presents high diversity and recombination in the over-summering zone of Gansu, China. Mycologia 102:44-53.

Enjalbert, J., Duan, X., Giraud, T., Vautrin, C., de Vallavieille-Pope, C., and Solignac, M. 2002. Isolation of twelve microsatellite loci, using an enrichment protocol, in the phytopathogenic fungus Puccinia striiformis f. sp. tritici. Mol. Ecol. Notes 2:563-565.

Fang, C. T. 1944. Physiological specialization of Puccinia striiformis Erikss. and Henn. in China. Phytopathology 34:1020-1024.

Hu, X. P., Li, J. J., Wang, Y. T., Wang, B. T., Li, Q., Kang, Z. S., Yang, M. N., Peng, Y. L., Liu, T. G., Chen, W. Q., and Xu, X. M. 2012. Race composition of Puccinia striiformis f. sp. tritici in Tibet, China. Plant Dis. 96:1615-1620.

Kang, Z., Zhao, J., Han, D., Zhang, H., Wang, X., Wang, C., Han, Q., Guo, J., and Huang, L. 2010. Status of wheat rust research and control in China. Pages 50-69 in: BGRI 2010 Tech. Workshop Oral Presentations, Full Papers, and Abstracts, 30-31 May, St. Petersburg, Russia. http://www.globalrust.org/sites/default/files/ 2010\%20BGRI\%20Plenary\%20papers.pdf, accessed October 23, 2015.

Kang, Z. S., Li, Z. Q., and Zhang, S. C. 1987. A preliminary study of pathogenic strain to Lovrin 13 of yellow rust of wheat. Acta Univ. Septentrionali Occident. Agric. 15:105-106.

Kosman, E., and Leonard, K. J. 2007. Conceptual analysis of methods applied to assessment of diversity within and distance between populations with asexual or mixed mode of reproduction. New Phytol. 174:683-696.

Li, Z. Q., and Zeng, S. M. 2002. Wheat Stripe Rust in China. China Agriculture Press, Beijing.

Liang, J. M., Wan, Q., Luo, Y., and Ma, Z. H. 2013. Population genetic structures of Puccinia striiformis in Ningxia and Gansu provinces of China. Plant Dis. 97: 501-509.

Line, R. F., and Qayoum, A. 1992. Virulence, aggressiveness, evolution, and distribution of races of Puccinia striiformis (the cause of stripe rust of wheat) in North America, 1968-87. U. S. Dep. Agric. Agric. Res. Serv. Tech. Bull. 1788.

Liu, K., and Muse, S. V. 2005. PowerMarker: An integrated analysis environment for genetic marker analysis. Bioinformatics 21:2128-2129.

Liu, T. G., Peng, Y. L., and Zhang, Z. Y. 2010. First detection of virulence in Puccinia striiformis f. sp. tritici in China to resistance genes Yr24 (=Yr26) present in wheat cultivar Chuanmai 42. Plant Dis. 94:1163.

Liu, X. F., Huang, C., Sun, Z. Y., Liang, J. M., Luo, Y., and Ma, Z. H. 2011 Analysis of population structure of Puccinia striiformis in Yunnan Province of China by using AFLP. Eur. J. Plant Pathol. 129:43-55.

Lu, N. H., Wang, J. F., Chen, X. M., Zhan, G. M., Chen, C. Q., Huang, L. L., and Kang, Z. S. 2011. Spatial genetic diversity and interregional spread of Puccinia striiformis f. sp. tritici in Northwest China. Eur. J. Plant Pathol. 131:685-693.

Mboup, M., Leconte, M., Gautier, A., Wan, A. M., Chen, W., de Vallavieille-Pope, C., and Enjalbert, J. 2009. Evidence of genetic recombination in wheat yellow rust populations of a Chinese oversummering area. Fungal Genet. Biol. 46: 299-307.

Nei, M. 1972. Genetic distance between populations. Am. Nat. 106:283-292.

Pasquali, M., Komjati, H., Lee, D., and Bayles, R. 2010. SRAP technique efficiently generate polymorphisms in Puccinia striiformis isolates. J. Phytopathol. 158: 708-771.

Peakall, R., and Smouse, P. E. 2006. GENALEX 6: Genetic Analysis in Excel. Population Genetic Software for Teaching and Research. Mol. Ecol. Notes 6: 288-295.

Pritchard, J. K., Stephens, M., and Donnelly, P. 2000. Inference of population structure using multilocus genotype data. Genetics 155:945-959.

Rambaut, A., and Drummond, A. 2010. FigTree V1. 3.1. Institute of Evolutionary Biology, the University of Edinburgh, Edinburgh, UK.

Shan, W. X., Chen, S. Y., and Kang, Z. S. 1998. Genetic diversity in Puccinia striiformis Westend. f. sp. tritici revealed by pathogen genome specific repetitive sequence. Can. J. Bot. 76:587-595.

Sharma-Poudyal, D., Chen, X. M., Wan, A. M., Zhan, G. M., Kang, Z. S., Cao, S. Q., Jin, S. L., Morgounov, A., Akin, B., Mert, Z., Shah, S. J. A., Bux, H., Ashraf, M., Sharma, R. C., Madariaga, R., Puri, K. D., Wellings, C., Xi, K. Q., Manninger, K., Wanyera, R., Ganzález, M. I., Koyda, M., Sanin, S., and Patzek, L. J. 2013. Virulence characterization of international collections of the wheat stripe rust pathogen, Puccinia striiformis f. sp. tritici. Plant Dis. 97:379-386.

Stubbs, R. 1985. Stripe rust. Pages 61-101 in: The Cereal Rusts II: Diseases, Distribution, Epidemiology and Control. A. P. Roelfs and W. R. Bushnell, eds. Academic Press, Inc., New York.

Wan, A. M., and Chen, X. M. 2014. Virulence characterization of Puccinia striiformis $\mathrm{f}$. sp. tritici using a new set of $Y r$ single-gene line differentials in the United States in 2010. Plant Dis. 98:1534-1542.

Wan, A. M., Chen, X. M., and He, Z. H. 2007. Wheat stripe rust in China. Aust. J. Agric. Res. 58:605-619.

Wan, A. M., Zhao, Z. H., Chen, X. M., He, Z. H., Jin, S. L., Jia, Q. Z., Yao, G., Yang, J. X., Wang, B. T., Li, G. B., Bi, Y. Q., and Yuan, Z. Y. 2004. Wheat stripe rust epidemic and virulence of Puccinia striiformis f. sp. tritici in China in 2002. Plant Dis. 88:896-904.

Wang, K. N., Hong, X. W., Si, Q. M., Wang, J. X., and Shen, J. P. 1963. Studies on the physiological specialization of stripe rust of wheat in China. J. Plant Prot. 2: 23-35. (In Chinese)

Wellings, C. R. 2011. Global status of stripe rust: A review of historical and current threats. Euphytica 179:129-141.

Wu, L. R., Yang, H. A., Yuan, W. H., Song, W. Z., Yang, J. X., Li, Y. F., and Bi, Y. Q. 1993. On the physiological specialization of stripe rust of wheat in China during 1985-1990. Acta Phytopathol. Sin. 23:269-274 (In Chinese).

Yeh, F. C., Yang, R. C., Boyle, T. 1997. POPGENE, version 1.21. CIFOR and University of Alberta, Edmonton, Canada.

Zeng, S. M., and Luo, Y. 2006. Long-distance spread and interregional epidemics of wheat stripe rust in China. Plant Dis. 90:980-988.

Zhan, G. M., Chen, X. M., Kang, Z. S., Huang, L. L., Wang, M. N., Wan, A. M., Cheng, P., Cao, S. Q., and Jin, S. L. 2012. Virulence and molecular comparison of Puccinia striiformis f. sp. tritici populations in China and the United States. Fungal Biol. 116:643-653. 